\title{
Heroin use impairs smoking cessation among Australian prisoners
}

Devon Indig ${ }^{1,2^{* \dagger}}$, Alex D Wodak ${ }^{3 \dagger}$, Robyn L Richmond ${ }^{2 \dagger}$, Tony G Butler ${ }^{4 \dagger}$, Vicki A Archer ${ }^{1 \dagger}$ and Kay A Wilhelm ${ }^{5,6 \dagger}$

\begin{abstract}
Background: Prisoners have extremely high rates of smoking with rates 3-4 times higher than the general community. Many prisoners have used heroin. The aims of this study were to investigate the impact of heroin use on smoking cessation and the social determinants of health among prisoners.

Methods: Secondary analysis of data from a randomised controlled trial of a multi-component smoking cessation intervention involving 425 Australian male prisoners. Inmates who, prior to imprisonment, used heroin regularly were compared to those who did not use heroin regularly. Self-reported smoking status was validated at baseline and each follow-up by measuring carbon monoxide levels. Readings exceeding 10 ppm were defined as indicating current smoking.
\end{abstract}

Results: Over half (56.5\%) of the participants had ever used heroin while $37.7 \%$ regularly (daily or almost daily) used heroin in the year prior to entering prison. Prisoners who regularly used heroin had significantly worse social determinants of health and smoking behaviours, including lower educational attainment, more frequent incarceration and earlier initiation into smoking. Prisoners who regularly used heroin also used and injected other drugs significantly more frequently. At 12-month follow-up, the smoking cessation of prisoners who had regularly used heroin was also significantly lower than prisoners who did not regularly use heroin, a finding confirmed by logistic regression.

Conclusions: Regular heroin use prior to imprisonment is an important risk factor for unsuccessful attempts to quit smoking among prisoners and is also associated with worse social determinants of health, higher drug use, and worse smoking behaviours. More effective and earlier smoking cessation interventions are required for particularly disadvantaged groups.

Trial registration: This trial is registered with the Australian New Zealand Clinical Trials Registry 12606000229572.

Keywords: Heroin, Prisoner, Smoking cessation, Nicotine dependence

\section{Background}

Smoking cessation efforts among the Australian community have led to a decline in smoking prevalence from a high of $72 \%$ of men and $26 \%$ of women in 1945 to a current regular smoking rate of $22 \%$ in men and $18 \%$ in women $[1,2]$. However, this trend is not seen in socially disadvantaged populations, such as prisoners, those with a mental illness, and illicit drug users [3-5]. The 2009

\footnotetext{
* Correspondence: d.indig@unsw.edu.au

${ }^{\dagger}$ Equal contributors

'Justice \& Forensic Mental Health Network, Centre for Health Research in Criminal Justice, Suite 302, Level 2, 152 Bunnerong Road, Pagewood, NSW 2035, Australia

${ }^{2}$ School of Public Health and Community Medicine, University of New South Wales, Sydney, NSW 2052, Australia

Full list of author information is available at the end of the article
}

New South Wales (NSW) Inmate Health Survey, which randomly sampled 996 prisoners in custody, reported $75 \%$ of male and $80 \%$ of female prisoners were current smokers [6]. Among those entering prisons across Australia, the rate of smoking was higher (85\%), and highest among prisoners reporting a history of injecting drug use (93\%) [7]. However, a substantial proportion of prisoners report wanting to stop smoking $[3,6,8,9]$.

The 2012 World Drug Report estimates that between $0.6 \%$ and $0.8 \%$ of the world's population aged between 15 and 64 years used opioid drugs with heroin the most widely used opioid [10]. In Australia in 2010, among those aged 14 and over $1.4 \%$ reported using heroin while $0.2 \%$ used heroin in the previous year [1]. The rate of heroin use was significantly higher among prisoners in

\section{Biomed Central}


NSW with $41 \%$ reporting having ever used heroin, 10\% using heroin on a daily/almost daily basis in the past year and 15\% having ever used heroin in prison [6]. Among Australian prison entrants who participated in a National Prisoner Health Census in 2009, 19\% of prisoners reported using heroin in the year before entering prison [11]. Heroin use among prisoners and the broader Australian community has decreased in the past decade following the heroin shortage of 2000, but rates are still high $[12,13]$.

Most people who currently use heroin or are on opioid substitution treatment (such as methadone or buprenorphine) also smoke cigarettes [9]. A recent Australian study found the prevalence of smoking was $84 \%$ among methadone users [14] and another study of heroin users reported $97 \%$ were smokers [15]. A qualitative study [16] asked drug users currently in treatment about the relationship between their smoking, methadone and drug use. The participants reported that drug use and smoking were complementary in managing side effects of both substances and withdrawal symptoms [16]. Smoking cessation rates among opioid-dependent people are lower than among the general population, however many still want to quit $[17,18]$.

Few studies have investigated how heroin use may affect smoking cessation intervention outcomes [19]. The aims of this paper were to assess the impact of regular heroin use in the year before entering prison on the social determinants of health, smoking behaviours (such as age of initiation and amount smoked per day) and success of quitting smoking among prisoners. As a high proportion of prisoners are current smokers and have used heroin, it is important that we improve our understanding of the relationship between the two in order to develop more effective smoking cessation interventions for this high risk and socially disadvantaged population.

\section{Methods}

\section{Study design}

This study involved a secondary analysis of data from a randomised controlled trial of a multi-component smoking cessation intervention among prisoners. This analysis compared prisoners who, prior to imprisonment, were regular (daily or almost daily use) heroin users with prisoners who were not regular heroin users (i.e. used heroin less than regularly). The trial recruited 425 male prisoners who received 13 weeks of nicotine replacement therapy, two sessions of brief cognitive behavioural therapy, had access to a Quitline, and were provided with smoking cessation support materials (e.g. a booklet designed by the investigators to assist with coping with prison stressors and a QUIT calendar). Participants were randomised to receive either active nortriptyline or placebo to assess the impact of the antidepressant on assisting participants to quit smoking. Ethics committees from the University of New South Wales, Justice Health NSW, Corrective Services NSW, the Aboriginal Health and Medical Research Council and Queensland Corrective Services approved the study. A full description of the methods, study intervention and results of the randomised controlled trial are reported elsewhere [20].

\section{Participants and recruitment}

Recruitment took place in 17 prisons in NSW $(\mathrm{N}=407)$ and one prison in Queensland $(\mathrm{N}=18)$ among prisoners who were current smokers and who indicated they wished to quit smoking. Between August 2006 and September 2009, 1,751 prisoners expressed interest in participating in the study and were assessed by a research nurse and doctor regarding the selection criteria. The majority $(\mathrm{N}=1,315)$ were considered ineligible for the following reasons: having less than six months left on their sentence (35\%), being on psychiatric medication or having a history of psychiatric illness (40\%) or a history of cardiac disease (5\%). Female prisoners were considered ineligible, as they only constitute $7 \%$ of the NSW prisoner population and generally have shorter sentences [21]. All participants provided written informed consent and were paid $\$ 10$ for each interview completed. Participants were followed up both in prison and the community at 3, 6 and 12 months to assess the point prevalence, continuous abstinence and smoking reduction. Follow-up rates were $90 \%$ at 3 months, $87 \%$ at 6 months, and $80 \%$ at 12 months, with no difference in follow-up rates for participants in the active nortriptyline and placebo groups. There was also no significant difference among participants who were regular or not regular heroin users regarding their assignment to treatment or placebo group, or with regard to their rate of follow-up.

\section{Questionnaires and measures}

Participants were administered a baseline questionnaire face-to-face by research nurses. The baseline questionnaire included questions on socio-demographics, offending history, smoking behaviours, smoking history, physical health, mental health and alcohol and other drug use. The follow-up questionnaires included most of the same measures in the baseline. The questions related to use of heroin (and all drugs) including if they 'ever used' or 'used regularly (daily/almost daily) in the 12 months before prison'. Smoking behaviours were measured using questions related to the number of cigarettes smoked before prison, years of regular smoking and prior quit attempts. Nicotine dependence was assessed using the Fagerström Test for Nicotine Dependence [22].

The primary smoking cessation outcome measures were point prevalence, continuous abstinence and 50\% 
reduction in number of cigarettes smoked (relative to baseline) measured at 12 months. These outcome measures were determined on an intention-to-treat basis [23]: if a participant missed a particular follow-up they were regarded as a smoker at that time period. Self-reported smoking status was validated at baseline and each followup by measuring carbon monoxide levels and readings exceeding $10 \mathrm{ppm}$ were classified as a smoker [24].

\section{Statistical analysis}

Questionnaires were double-key entered into an electronic database and the data were cleaned for potential errors. Statistical analysis was performed using SAS version 9.2 [25]. Descriptive and inferential statistics (including chi-square and t-tests) were used to determine any statistically significant differences $(\mathrm{p} \leq 0.05)$ across a range of characteristics for inmates who regularly used heroin compared with those who had not regularly used heroin in the year before prison. For the smoking cessation outcome variables, intention-to-treat analyses [23] were utilised with missing data classified as either continuing smoking or not reducing the amount smoked by $50 \%$. This included chi-square analysis and logistic regression for the major outcome variables of point prevalence and continuous abstinence at 12 months. There were no significant differences in the follow-up rates for regular versus non-regular heroin users. In the logistic regression models, potential confounders were controlled for including any socio-demographics and other drug use characteristics which were significant.

\section{Results}

\section{Socio-demographics, drug use and offending history by regular heroin users}

Among the 425 male participants, over half (56.5\%) had ever used heroin and $37.7 \%$ regularly (daily/almost daily) used heroin in the 12 months before entering prison. Prisoners who had regularly used heroin before prison were significantly younger than those who had not used heroin regularly (Table 1). Other socio-demographic characteristics which were significantly worse for prisoners who were regular heroin users included: institutionalisation as a child, leaving school with no qualification and at a younger age and being homeless prior to entering prison.

Prisoners with a history of regular heroin use in the year before entering prison were significantly more likely to have ever used all other types of drugs, as well as regularly (daily or almost daily) using all other types of drugs prior to prison than prisoners who were not regular heroin users prior to entering prison. Similarly, prisoners who were regular heroin users prior to entering prison were significantly more likely to have been previously incarcerated and had twice as many adult prison terms than prisoners who were not regular heroin users.

\section{Smoking history, cessation behaviours and outcomes by regular heroin users}

The mean ages for first smoking tobacco and for smoking tobacco on a daily basis were significantly lower for prisoners who were regular heroin users compared to those who were not regular heroin users (Table 2). There were no significant differences between participants who regularly used heroin and those who did not with regard to the quantity of tobacco smoked or nicotine dependence score. Participants who had regularly used heroin were significantly less likely to have attempted unsuccessfully to quit smoking in the past year, but there were no significant differences in the number of quit attempts.

The outcomes of the smoking cessation intervention identified lower rates of quitting smoking for point prevalence $(5.0 \%$ vs. $18.5 \%, \mathrm{P}<0.01)$ and continuous abstinence $(3.8 \%$ vs. $16.6 \%, \mathrm{P}<0.01)$ at 12 -month follow-up for participants who were regular heroin users prior to prison. There were no significant differences between participants who were regular heroin users and those who were not with regard to having taken the study medication (NOR), nor with the outcome of reducing the quantity of tobacco smoked by $50 \%$ at 12 months.

\section{Predictors of smoking abstinence}

Table 3 identifies potential predictors of smoking abstinence (both point prevalence and continuous abstinence) at 12 months, including socio-demographic, drug use and smoking behaviours which were significantly different between participants who, before entering prison, were regular heroin users and those who were not. The crude odds ratio for both models identified the following predictors of successfully quitting smoking at 12 months: being in prison for the first time, being in prison for five or more years, not being a regular heroin user and not being a regular user of other drugs (excluding heroin). When these predictors which were significant in the crude model were incorporated into the logistic regression model, not being a regular heroin user was the primary predictor for both point prevalence $(\mathrm{OR}=3.81$, $95 \%$ CI: $1.65-8.78)$ and continuous abstinence $(\mathrm{OR}=4.29$, 95\% CI: 1.69-10.90).

\section{Discussion}

This paper concludes that heroin use in the year before entering prison is associated with a reduced likelihood of stopping smoking at 12 months following a multicomponent smoking cessation intervention. This finding remained significant after controlling for regular use of drugs other than heroin, which strengthens the specificity of this association. Though there are a number of studies identifying the importance of implementing smoking cessation interventions among people in opioid treatment programs $[5,26,27]$, no studies were found which 
Table 1 Socio-demographics, drug use and offending history by regular use of heroin in year before prison Not regularly used heroin \% $\quad$ Regularly used heroin \% $\quad$ Total men \% $(\mathrm{N}=\mathbf{2 6 5})$ $(\mathrm{N}=160)$ $(\mathrm{N}=425)$

\section{Socio-demographics}

Age group

$\begin{array}{ll}<25 \text { years } & 25.3 \\ 25-29 \text { years } & 17.4 \\ 30-39 \text { years } & 23.4 \\ 40+\text { years } & 34.0 \\ \text { Mean age } & 34.4\end{array}$

25.3

17.4

23.4

34.0

34.4

(+SD; Range)

Aboriginal origin

Born in Australia

Left school no qualification

Mean age left school

$$
\text { (+SD; Range) }
$$

Institutionalised as a child (juvenile detention and/or placed in care)

Homeless prior to prison

Employed while in prison

\section{Ever use drugs by drug type}

Cannabis

Amphetamines

Cocaine

Heroin

Other opiates

Tranquilisers

Any drugs (other than heroin)

Any drugs

Regularly (daily or almost daily) use drugs prior to prison by drug type

Cannabis

Amphetamines

Cocaine

Other opiates

Tranquilisers

Any drugs (other than heroin)

Any drugs

\section{Offending history}

Previously incarcerated

Median number adult prison terms

$$
\text { (+SD; Range) }
$$

Median years in prison at baseline

$$
\text { (+SD; Range) }
$$

Median sentence length in years

$$
\text { (+SD; Range) }
$$

(11.2; 18-65)

14.3

74.8

39.3

15.5

$(1.7 ; 12-26)$

31.3

4.5

79.3

89.1

66.0

44.2

30.1

18.9

22.6

92.1

92.5

Abbreviations: $\mathrm{SD}=$ standard deviation $\mathrm{NS}=\mathrm{not}$ significant.

$\begin{array}{lll}19.4 & 23.1 & \\ 24.4 & 20.0 & \mathrm{P}<0.01 \\ 37.5 & 28.7 & \\ 18.9 & 28.2 & \\ 32.0 & 33.5 & \mathrm{P}<0.02 \\ (8.0 ; 19-54) & (10.2 ; 18-65) & \\ 16.3 & 15.1 & \mathrm{NS} \\ 75.0 & 74.9 & \mathrm{NS} \\ 50.6 & 43.5 & \mathrm{P}<0.03 \\ 14.6 & 15.1 & \mathrm{P}<0.01 \\ (2.3 ; 0-19) & (2.0 ; 0-26) & \\ 48.8 & 37.9 & \mathrm{P}<0.01 \\ & & \\ 11.3 & 7.1 & \mathrm{P}<0.01 \\ 60.0 & 72.0 & \mathrm{P}<0.01\end{array}$

98.8

95.0

81.9

100.0

66.9

66.9

100.0

100.0

92.7

$P<0.01$

76.9

58.4

$P<0.01$

$P<0.01$

$P<0.01$

$P<0.01$

$P<0.01$

$P<0.01$

$\mathrm{P}<0.01$

95.3

60.5

$P<0.01$

60.1

56.9

37.5

35.6

92.5

100.0

48.7

$P<0.01$

36.2

$P<0.01$

16.0

$P<0.01$

17.4

$P<0.01$

77.9

$P<0.01$

80.9

$P<0.01$

\section{6}

63.8

$P<0.01$

4.0

(2.8; 1-15)

2.0

$P<0.01$

(2.9; 1-20)

1.8

1.9

NS

(4.2; 0.02-27.1)

(4.1; 0.03-23.2)

3.6

NS 
Table 2 Smoking history, cessation behaviours and outcomes by regular use of heroin in year before prison

\begin{tabular}{|c|c|c|c|c|}
\hline & $\begin{array}{l}\text { Not regularly used heroin \% } \\
(\mathrm{N}=265)\end{array}$ & $\begin{array}{l}\text { Regularly used heroin \% } \\
(\mathrm{N}=160)\end{array}$ & $\begin{array}{l}\text { Total men \% } \\
(\mathrm{N}=425)\end{array}$ & P-value \\
\hline \multicolumn{5}{|l|}{ Smoking behaviours } \\
\hline Mean age first smoked tobacco & 14.1 & 13.0 & 13.7 & $P<0.02$ \\
\hline (+SD; Range) & $(4.8 ; 5-39)$ & $(3.1 ; 5-22)$ & $(4.3 ; 5-39)$ & \\
\hline Mean age first smoked tobacco daily & 16.0 & 14.6 & 15.5 & $P<0.01$ \\
\hline (+SD; Range) & $(4.6 ; 5-39)$ & $(3.2 ; 7-30)$ & $(4.2 ; 5-39)$ & \\
\hline Mean years smoked tobacco & 20.3 & 19.0 & 19.8 & NS \\
\hline (+SD; Range) & $(11.2 ; 0-52)$ & $(8.4 ; 3-46)$ & $(10.2 ; 0-52)$ & \\
\hline Mean carbon monoxide reading & 14.1 & 14.5 & 14.3 & NS \\
\hline (+SD; Range) & $(7.5 ; 1-43)$ & $(8.2 ; 3-59)$ & $(7.8 ; 1-59)$ & \\
\hline Mean cigarettes smoked per day & 23.1 & 23.3 & 23.2 & NS \\
\hline (+SD; Range) & $(10.3 ; 3-75)$ & $(8.9 ; 5-60)$ & $(9.8 ; 3-75)$ & \\
\hline Smoke $20+$ cigarettes per day & 67.6 & 74.4 & 70.1 & NS \\
\hline High tobacco dependence (Fagerström 6+) & 80.8 & 86.3 & 82.8 & NS \\
\hline Share a cell with a smoker & 32.2 & 35.6 & 33.5 & NS \\
\hline Smoke White Ox (loose tobacco) & 97.0 & 97.5 & 97.2 & NS \\
\hline \multicolumn{5}{|l|}{ Smoking cessation behaviours } \\
\hline Mean times tried to quit smoking & 2.9 & 2.2 & 2.6 & NS \\
\hline (+SD; Range) & $(8.6 ; 0-128)$ & $(2.6 ; 0-20)$ & $(7.9 ; 0-128)$ & \\
\hline \multicolumn{5}{|l|}{ Quitting behaviours in past year } \\
\hline Given up more than one month & 14.0 & 11.3 & 12.9 & NS \\
\hline Tried to give up unsuccessfully & 64.2 & 53.8 & 60.2 & $P<0.04$ \\
\hline Lower tar or nicotine content & 7.9 & 4.4 & 6.6 & NS \\
\hline Reduced amount tobacco smoked & 50.2 & 43.8 & 47.8 & NS \\
\hline Quit on purpose for 24 hours & 57.0 & 48.1 & 53.7 & NS \\
\hline Any type of quitting behaviour & 76.2 & 68.8 & 73.4 & NS \\
\hline \multicolumn{5}{|l|}{ Smoking cessation intervention outcomes } \\
\hline Active NOR versus placebo NOR & 49.4 & 46.9 & 48.5 & NS \\
\hline Quit smoking at 12 months: point prevalence & 18.5 & 5.0 & 13.4 & $P<0.01$ \\
\hline Quit smoking at 12 months: continuous abstinence & 16.6 & 3.8 & 11.2 & $P<0.01$ \\
\hline $50 \%$ smoking reduction at 12 months & 76.2 & 72.2 & 74.7 & NS \\
\hline
\end{tabular}

Abbreviations: SD = standard deviation; NS = not significant; NOR = nortriptyline.

investigated regular heroin use as a possible risk factor for an unsuccessful quit smoking attempt. As nearly half of smokers die of a tobacco-related illness [28] and the annual mortality rate for heroin-dependent people is a further $2 \%$ [29], the combined risk factors of smoking and heroin dependence have important public health implications.

The findings of this study suggest that future smoking cessation interventions should consider identifying concurrent drug addictions (particularly heroin) and identify strategies to deal with all drug problems at the same time. There is a growing body of evidence supporting multiple behaviour change interventions which can be applied to addressing smoking cessation and drug use $[30,31]$. A recent meta-analysis of the outcomes of smoking cessation interventions among participants in drug and alcohol treatment identified that smoking cessation interventions were associated with a $25 \%$ increase in long-term drug and alcohol abstinence [32], a finding supported by other studies $[33,34]$. As many persons undergoing treatment for heroin dependence in the community may later enter prison [35], strong support to quit smoking should be provided as a routine in all drug treatments for heroin dependence.

Prisoners with a history of regular heroin use in the year prior to entering prison had significantly poorer social determinants of health such as poor educational attainment, higher involvement in out-of-home care, and were also more likely to be homeless. These determinants are 
Table 3 Predictors (crude and adjusted odds ratios) of smoking abstinence at 12 months

\begin{tabular}{|c|c|c|c|c|}
\hline & \multicolumn{2}{|l|}{ Point prevalence } & \multicolumn{2}{|l|}{ Continuous abstinence } \\
\hline & Crude & Adjusted & Crude & Adjusted \\
\hline & Odds Ratio $(95 \% \mathrm{Cl})$ & Odds ratio $(95 \% \mathrm{Cl})$ & Odds Ratio $(95 \% \mathrm{Cl})$ & Odds ratio $(95 \% \mathrm{Cl})$ \\
\hline Active NOR versus placebo NOR & $0.81(0.46-1.42)$ & $0.89(0.49-1.62)$ & $0.98(0.54-1.77)$ & $1.07(0.57-2.00)$ \\
\hline Age $35+$ years & $1.86(1.06-3.25) \dagger$ & $1.46(0.77-2.75)$ & $1.64(0.91-2.97)$ & $1.36(0.70-2.65)$ \\
\hline Aboriginal origin & $0.50(0.19-1.31)$ & $0.53(0.19-1.48)$ & $0.60(0.23-1.56)$ & $0.61(0.22-1.72)$ \\
\hline Left school no qualification & $0.55(0.31-1.01)$ & - & $0.70(0.38-1.29)$ & - \\
\hline Institutionalised as a child & $0.66(0.36-1.21)$ & - & $0.60(0.32-1.16)$ & - \\
\hline Homeless prior to prison & $0.70(0.21-2.39)$ & - & $0.82(0.24-2.82)$ & - \\
\hline Employed while in prison & $1.74(0.87-3.48)$ & - & $1.89(0.89-4.02)$ & - \\
\hline Tried to give up unsuccessfully & $0.89(0.51-1.57)$ & - & $0.75(0.41-1.36)$ & - \\
\hline First time in prison & $2.19(1.25-3.84) \dagger$ & $1.47(0.79-2.72)$ & $2.52(1.38-4.57) \dagger$ & $1.68(0.88-3.20)$ \\
\hline Incarcerated $5+$ years at baseline & $2.67(1.44-4.96) \dagger$ & $2.30(1.17-4.52) \dagger$ & $2.16(1.11-4.20) \dagger$ & $1.88(0.91-3.88)$ \\
\hline $\begin{array}{l}\text { Not regular drug use (excluding heroin) in year } \\
\text { prior to prison }\end{array}$ & $2.37(1.33-4.19) \dagger$ & $1.31(0.65-2.62)$ & $2.39(1.30-4.39) \dagger$ & $1.33(0.64-2.75)$ \\
\hline Not regular heroin use in year prior to prison & $4.31(1.98-9.36) \dagger$ & $3.81(1.65-8.78) \dagger$ & $5.11(2.13-12.29) \dagger$ & $4.29(1.69-10.90) \dagger$ \\
\hline
\end{tabular}

Abbreviations: $\mathrm{NOR}=$ nortriptyline $+\mathrm{P}<0.05$.

also important risk factors for smoking tobacco, and they reduce the success rate for smoking cessation interventions $[36,37]$. Further, participants who used heroin regularly prior to prison also were significantly more likely to have been previously incarcerated and had a median of twice as many previous times in prison compared to those who had not used heroin regularly. Increased involvement in the criminal justice system is likely to exacerbate poverty, homelessness and other social disadvantages which are associated with tobacco smoking [38].

Another key characteristic of prisoners who had regularly used heroin in the year before entering prison is that they started smoking at a younger age and reported significantly more other drug use than prisoners who did not report regular heroin use. It is well documented that drug and alcohol treatment services often fail to address underlying tobacco dependence [39-41]. Some reasons for this include inadequate staff knowledge and training for providing smoking cessation interventions, high smoking prevalence rates among staff, and ambivalent attitudes and beliefs related to tobacco among staff [41]. These barriers to providing smoking cessation among people with drug and alcohol problems may be addressed through providing enhanced staff education and training in smoking cessation, supporting staff to quit smoking and creating a smoke-free environment for drug and alcohol treatment services [42]. The magnitude of the barriers to treatment provision and uptake for prisoners coupled with the major adverse biological and social factors associated with severe drug dependence [43], suggests that very powerful interventions to assist smoking cessation will be required to increase quit rates in this population.

\section{Limitations}

One limitation of this study is that heroin use was assessed by participant self-report, so may not reflect the true proportion of prisoners who had ever or recently used heroin. Some prisoners may have been concerned about admitting to an illegal behaviour while in prison. However, the use of independent research nurses was expected to improve the confidence of participants that their responses would be kept confidential. This study was also limited by only including males so cannot necessarily be generalised for female prisoners. Also, this study was also limited by its stringent inclusion and exclusion criteria, which were necessary in ensuring safe administration of nortriptyline, but which excluded a high proportion of men interested in quitting smoking. It is not possible to determine if the men who were eligible were more or less likely to use heroin than those who were not so the generalisability of these findings must be considered with caution. Another limitation of the study is that participants were not asked if they were on an opioid substitution program or if they were currently using heroin so we cannot determine if this had an impact on smoking cessation success. Despite these limitations, this study has a number of strengths including: a strong follow-up rate of $80 \%$ at 12 months; recruitment across nearly all male prisons in NSW; adherence to a rigorous study protocol; and utilising a tailored multi-component smoking cessation intervention that was piloted among prisoners [3].

\section{Conclusions}

The key finding of this study was that, before entering prison, prisoners who had regularly used heroin were 
significantly less likely to have successfully quit smoking than prisoners who did not report regular heroin use. This suggests that smoking cessation interventions for prisoners should take into account prisoners' recent drug (particularly heroin) use in order to develop an effective intervention which tackles both smoking and illicit drug use. More research may assist in determining if these interventions should occur as a combined model or separately and the optimal timing of their implementation.

Many prisoners wish to quit smoking. Incarceration presents an opportune time to attempt engaging prisoners in smoking cessation interventions. More research is needed to determine how best to support prisoners who regularly used heroin to quit smoking. Some evidence suggests that when people are able to quit smoking, they are better able to stop using illicit drugs, which may result in reductions in re-offending, as well as significant improvements in health and well-being.

\section{Abbreviations}

SD: Standard deviation; NS: Not significant; NOR: Nortriptyline; NSW: New South Wales.

\section{Competing interests}

The authors declare that they have no competing interests.

\section{Authors' contributions}

$\mathrm{RR}, \mathrm{KW}, \mathrm{TB}$ and $\mathrm{AW}$ were involved in all aspects of this study from conceptualisation, funding, and development of questionnaire for baseline and follow-up assessments. DI and VA joined the study and made substantial contributions to data acquisition. DI conducted the data analysis and prepared the draft manuscript. All authors have been involved in data interpretation, finalising the manuscript, and have given final approval of the version to be published.

\section{Acknowledgements}

This work was supported by the National Health and Medical Research Council (Project Grant 350829) the NSW Department of Health, Justice \& Forensic Mental Health Network and the Queensland Department of Health. NRT was provided free-of-charge by GlaxoSmithKline. This trial from which these findings were generated is registered with the Australian New Zealand Clinical Trials Registry \#12606000229572.

We would like to acknowledge the prison research nurses, Anne Cole and Phe Affleck, who administered the baseline questionnaires and tenaciously followed up the prisoners, and Drs Andrew Zdenkowski, Laurie Varga and Ken Kuen who conducted the medical assessment of all participants for the study. We would also like to acknowledge Dr Alun Richards, Executive Director - Offender Health Services Directorate, Queensland Health, for introducing the study into Borallon Correctional Centre in Queensland. Invaluable assistance was provided by the research nurses Elizabeth Baxter, Luke McCreddie, Anne Cole and Phe Affleck in NSW and Adair Behrends in Queensland, as well as the Justice Health Chief Pharmacists Hana Abdalla and Steven Crago, A/Data Co-ordinator Robyn Hetherington and Megan Kent A/Services Manager. Quitline was provided to the inmates by Quitline staff: Bronwyn Crosby, David Lester, Leah McLeod, Jennifer Blundell, Jake Docker, Jillian MacDonald and Matthew Nelson in NSW and Kerryn Nicks in Queensland. We would also like to acknowledge Joanne Hunnisett who entered and cleaned the considerable data bank, and Fran Hyslop who also worked on the ethics applications and the literature review.

\section{Author details}

'Justice \& Forensic Mental Health Network, Centre for Health Research in Criminal Justice, Suite 302, Level 2, 152 Bunnerong Road, Pagewood, NSW 2035, Australia. ${ }^{2}$ School of Public Health and Community Medicine, University of New South Wales, Sydney, NSW 2052, Australia. ${ }^{3}$ Alcohol and Drug Service, St Vincent's Hospital, 390 Victoria Street, Sydney, NSW 2010, Australia.
${ }^{4}$ Kirby Institute, University of New South Wales, Sydney, NSW 2052, Australia. ${ }^{5}$ Faces in the Street, Institute of Urban Mental Health and Wellbeing, St Vincent's Hospital, Level 6, O'Brien Centre, 390 Victoria Street, Sydney, NSW 2010, Australia. ${ }^{6}$ School of Psychiatry, University of New South Wales, Sydney, NSW 2052, Australia.

Received: 3 July 2013 Accepted: 9 December 2013

Published: 19 December 2013

\section{References}

1. Australian Institute of Health and Welfare: 2010 National Drug Strategy Household Survey Report. Drug Statistics Series No. 25. Canberra: Australian Institute of Health and Welfare; 2011.

2. Woodward SD: Trends in cigarette consumption in Australia. Aust N Z J Med 1984, 14:405-407.

3. Richmond RL, Butler T, Belcher JM, Wodak A, Wilhelm KA, Baxter E: Promoting smoking cessation among prisoners: feasibility of a multi-component intervention. Aust NZ J Public Health 2006, 30:474-478.

4. Richter KP, Ahluwalia HKA, Mosier MC, Nazir N, Ahluwalla JS: A populationbased study of cigarette smoking among illicit drug users in the United States. Addiction 2002, 97:861-869.

5. Baker A, Ivers R, Bowman J, Butler T, Kay-Lambkin FJ, Wye P, et al: Where there's smoke, there's fire: High prevalence of smoking among some sub-populations. Drug Alcohol Rev 2006, 25:85-96.

6. Indig D, Topp L, Ross B, Mamoon H, Border B, Kumar S, et al: 2009 NSW Inmate Health Survey: Key Findings Report. Sydney: Justice Health; 2010.

7. Butler T, Lim D, Callander D: National Prison Entrants'Bloodborne Virus and Risk Behaviour Survey Report 2004, 2007 \& 2010. Sydney: Kirby Institute (University of New South Wales) and National Drug Research Institute (Curtin University); 2011.

8. Cropsey K, Eldridge GD, Ladner T: Smoking among female prisoners: an ignored public health epidemic. Addict Behav 2004, 29:425-431.

9. Clarke JG, Stein MD, McGarry KA, Gogineni A: Interest in smoking cessation among injection drug users. Am J Addiction 2001, 10:159-166.

10. United Nations Office on Drugs and Crime: World Drug Report 2012. United Nations Publication, Sales No. E.12.X1.1. New York: United Nations Office on Drugs and Crime; 2012

11. Australian Institute of Health and Welfare: The health of Australia's prisoners 2009. AlHW Cat No. PHE 123. Canberra: Australian Institute of Health and Welfare; 2010

12. Wodak $A$ : What caused the recent reduction in heroin supply in Australia. Int J Drug Pol 2008, 19:279-286.

13. Degenhardt L, Day C, Dietze P, Pointer S, Conroy E, Collins L, et al: Effects of a sustained heroin shortage in three Australian states. Addiction 2005, 100:908-920.

14. Bowman J, Wiggers J, Colyvas K, Wye P, Walsh RA, Bartlem K: Smoking cessation among Australian methadone clients: prevalence, characteristics and a need for action. Drug Alcohol Rev 2012, 31:507-513.

15. Pajusco B, Chiamulera C, Quaglio G, Moro L, Casari R, Amen G, et al: Tobacco addiction and smoking status in heroin addicts under methadone vs. buprenorphine therapy. Int J Environ Res Publ Heal 2012, 9:932-942.

16. McCool RM, Richter KP: Why do so many drug users smoke? I Subst Abuse Treat 2003, 25:43-49.

17. Sullivan MA, Covey LS: Current perspectives on smoking cessation among substance abusers. Curr Psych Rep 2002, 4:388-396.

18. Clemmey P, Brooner R, Chutuape MA, Kidorf M, Stitzer M: Smoking habits and attitudes in a methadone maintenance treatment population. Drug Alcohol Dep 1997, 44:123-132.

19. Richter KP, Gibson CA, Ahluwalia JS, Schmelzle KH: Tobacco use and quit attempts among methadone maintenance clients. Am J Public Health 2001, 91:296-299.

20. Richmond $\mathrm{R}$, Indig $\mathrm{D}$, Butler $\mathrm{T}$, Wilhelm $\mathrm{K}$, Archer $\mathrm{V}$, Wodak $\mathrm{A}$ : A randomised controlled trial of a smoking cessation intervention conducted among prisoners. Addiction 2013, 108:966-974.

21. Corben S: NSW inmate census 2011: summary of characteristics. Statistical publication no. 38. Corrective Services NSW: Sydney; 2011.

22. Heatherton $T$, Kozlowski L, Frecker R, Fagerström K: The fagerström test for nicotine dependence: a revision of the fagerström tolerance questionnaire. Brit J Addict 1991, 86:1119-1127. 
23. Wright CC, Sim J: Intention to treat approach to data from randomised controlled trials: a sensitivity analysis. J Clin Epidemiol 2003, 56:833-842.

24. Cropsey K, Eldridge GD, Weaver MF, Villabos GC, Stitzer ML: Expired carbon monoxide levels in self-reported smokers and non-smokers in prison. Nicotine Tob Res 2006, 8:652-659.

25. SAS Institute: The SAS System for Windows version 9.2. Cary, North Carolina: SAS Institute Inc.; 2007.

26. Richter KP, Ahluwalia JS: A case for addressing cigarette use in methadone and opioid treatment programs. J Addict Dis 2000, 19:35-52.

27. Hall SM, Prochaska JJ: Treatment of smokers with co-occuring disorders: Emphasis on integration in mental health and addiction treatment settings. Annu Rev Clin Psychol 2009, 5:409-431.

28. Ezzati M, Lopez AD: Estimates of global mortality attributable to smoking in 2000. Lancet 2003, 362:847-852.

29. Oppenheimer E, Tobutt C, Taylor C, Andrew T: Death and survival in a cohort of heroin addicts from London clinics: a 22-year follow-up study. Addiction 1994, 89:1299-1308.

30. Prochaska JJ, Spring B, Nigg CR: Multiple behaviour change research: an introduction and overview. Prev Med 2008, 46:181-188.

31. Goldstein MG, Whitlock EP, DePue J: Multiple behavioural risk factor interventions in primary care. Summary of research evidence. Am J Prev Med 2004, 27:61-79.

32. Prochaska JJ, Delucchi K, Hall SM: A meta-analysis of smoking cessation interventions with individuals in substance abuse treatment or recovery. J Consult Clin Psych 2004, 72:1144-1156.

33. Kalman D: Smoking cessation treatment for substance misusers in early recovery: a review of the literature. Subst Use Misuse 1998, 33:2021-2047.

34. Lemon SC, Friedmann PD, Stein MD: The impact of smoking cessation on drug abuse treatment outcome. Addict Behav 2003, 28:1323-1331.

35. Hall W, Doran C, Degenhardt L, Shepard D: Illicit opiate abuse. In Disease Control Priorities in Developing Countries. 2nd edition. Edited by Jamison DT Breman JG, Measham AR, Alleyne G, Claeson M, Evans DB, Jha P, Mills A, Musgrove P. Washington (DC): World Bank; 2006. Chapter 48.

36. Flint AJ, Novotny TE: Poverty status and cigarette smoking prevalence and cessation in the United States, 1983-1993: the independent risk of being poor. Tob Control 1997, 6:14-18.

37. Gilman SE, Abrams DB, Buka SL: Socioeconomic status over the life course and stages of cigarette use: initiation, regular use and cessation. J Epidemiol Commun H 2003, 57:802-808.

38. World Health Organisation: Social determinants of health: the solid facts. In Second edition. Edited by Richard W, Michael M. Denmark: World Health Organisation; 2003

39. Knudsen HK, Studts JL, Boyd S, Roman PM: Structural and cultural barriers to the adoption of smoking cessation services in addiction treatment organisations. J Addict Dis 2010, 29:294-305

40. Schroeder SA, Morris CD: Confronting a neglected epidemic: tobacco cessation for persons with mental illnesses and substance abuse problems. Annu Rev Publ Health 2010, 31:297-314.

41. Ziedonis DM, Guydish J, Williams JM, Steinberg M, Foulds J: Barriers and solutions to addressing tobacco dependence in addiction treatment programs. Alcohol Res Health 2006, 29:228-235.

42. Guydish J, Passalacqua E, Tajima B, Manser ST: Staff smoking and other barriers to nicotine dependence intervention in addiction treatment settings: a review. J Psycho Drugs 2007, 39:423-433.

43. Buchman DZ, Skinner W, Illes J: Negotiating the relationship between addiction, ethics and brain science. AJOB Neurosci 2010, 1:36-45

\section{Submit your next manuscript to BioMed Central and take full advantage of:}

- Convenient online submission

- Thorough peer review

- No space constraints or color figure charges

- Immediate publication on acceptance

- Inclusion in PubMed, CAS, Scopus and Google Scholar

- Research which is freely available for redistribution

Submit your manuscript at www.biomedcentral.com/submit
Ciomed Central 